\title{
Successful operation on a coronary arteriovenous fistula in a 74 year old woman
}

\author{
M J Brack, P J B Hubner, R K Firmin
}

Regional

Cardiothoracic Unit, Groby Road Hospital, Leicester M J Brack P J B Hubner R K Firmin

Correspondence to Dr M J Brack, Regional Cardiothoracic Unit, Groby Road Hospital, Leicester LE3 9QE

\begin{abstract}
Coronary arteriovenous fistulas are rare and are usually diagnosed in children or young adults. Most are believed to be congenital. A right coronary arteriovenous fistula was first diagnosed in a patient of 74. Despite her age the fistula was successfully operated on and her symptoms were relieved.
\end{abstract}

Coronary arteriovenous fistulas are rare and are usually diagnosed in children or young adults. ${ }^{1}$ Most occur as congenital anomalies but acquired fistulas may arise after thoracic trauma. ${ }^{23}$ The right coronary artery is most commonly affected, and it usually communicates with the right heart chambers or the pulmonary artery. ${ }^{4}$ In most instances the fistulas are small with insignificant shunts. This group of patients often remain symptom free. However, in the presence of larger shunts, congestive cardiac failure can occur, especially in the young or elderly. ${ }^{5}$

\section{Case report}

A 74 year old woman was referred in 1987 with a 7 year history of progressive dyspnoea and a one year history of paroxysmal nocturnal dyspnoea. She was considerably limited by her dyspnoea. In 1984 she presented to another hospital with mitral regurgitation and fever. She was treated for suspected infective endocarditis though no organism was isolated by culture. On follow up she continued to have a pansystolic murmur and the diagnosis was one of mitral regurgitation. She was referred for possible mitral valve replacement. In the past she had had a subtotal thyroidectomy for a thyroid adenoma. Her daily medication was digoxin $125 \mu \mathrm{g}$, frusemide $120 \mathrm{mg}$, amiloride $15 \mathrm{mg}$, and thyroxine $100 \mu \mathrm{g}$.

She was a sprightly woman of lean build. She was in atrial fibrillation (96 beats/minute) with a blood pressure of $150 / 90 \mathrm{~mm} \mathrm{Hg}$. The jugular venous pressure was raised to $4 \mathrm{~cm}$. There was clinical left and right ventricular enlargement. On auscultation the striking finding, not previously reported, was of a loud continuous murmur heard in the aortic area that radiated to the lower right sternal edge. At the mitral area there was a moderately loud pansystolic murmur referred to the left axilla. There was no peripheral oedema and the lung fields were clear.

The electrocardiogram showed atrial fibrillation, an axis of $0^{\circ}$, and incomplete right bundle branch block. The chest $x$ ray showed an enlarged heart (cardiothoracic ratio $70 \%$ ). Cross sectional and $M$ mode echocardiography showed normal mitral and aortic valves. The left ventricle was of normal size with normal contraction. Doppler echocardiography confirmed mitral regurgitation and no other abnormal flow patterns were detected.

Cardiac catheterisation was performed. Systolic and diastolic pressures were: right atrium $16 / 6 \mathrm{~mm} \mathrm{Hg}$, right ventricle $30 / 12$ $\mathrm{mm} \mathrm{Hg}$, pulmonary artery $32 / 12 \mathrm{~mm} \mathrm{Hg}$, pulmonary capillary vein $18 / 10 \mathrm{~mm} \mathrm{Hg}$, aorta $120 / 60 \mathrm{~mm} \mathrm{Hg}$, left ventricle $120 / 10 \mathrm{~mm} \mathrm{Hg}$. There was a step up in oxygen saturation at the level of the right ventricle and the following oxygen saturations were recorded: aorta $95 \%$, inferior vena cava $63 \%$, superior vena cava $56 \%$, right atrium $65 \%$, right ventricle $68 \%$, pulmonary artery $74 \%$. The pulmonary to systemic flow ratio was $1 \cdot 7: 1$. The left ventricular angiogram showed a normal sized left ventricle with good contraction. There was mild to moderate mitral regurgitation. Aortography showed a normal aortic valve ring with mild dilatation of the aorta above it. There was no aortic regurgitation. The right coronary artery was very large and tortuous, approximately three times the normal calibre (fig 1). Contrast passed from the right coronary artery via a fistula into an aneurysmal coronary sinus (fig 2). The left coronary artery was also abnormal, being dilated and tortuous with contrast passing via the distal left anterior descending artery to the area of the fistula.

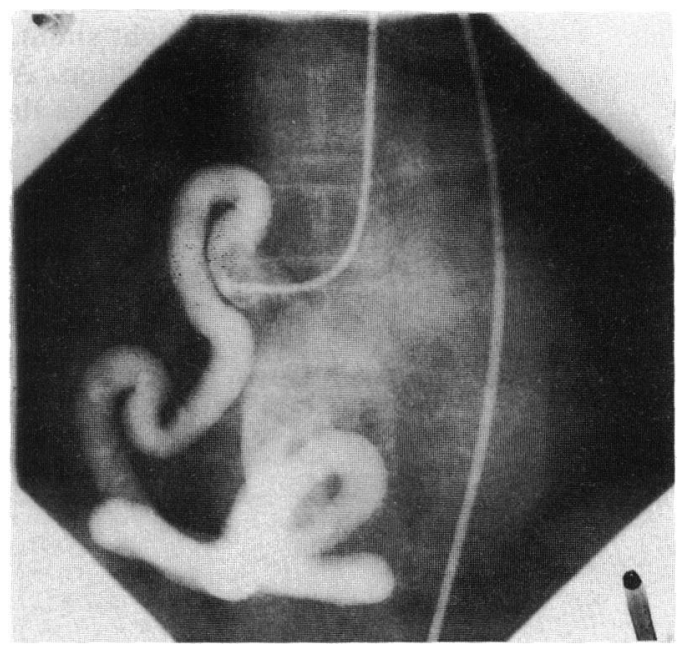

Figure 1 Right coronary angiogram showing a dilated tortuous vessel. 


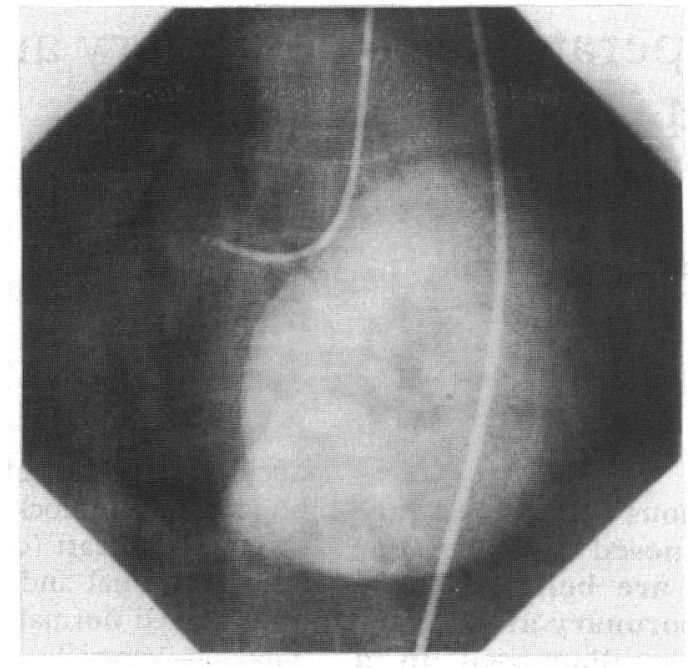

Figure 2 A late film showing contrast in aneurysmal coronary sinus.

Because she was considerably limited by her symptoms she was accepted for surgery. At operation a very dilated right coronary artery was opened distally showing a single $1 \mathrm{~cm}$ fistula opening into an aneurysmal coronary sinus. This area was obliterated with $5 / 0$ prolene stitches and then the coronary artery was double tied proximal to the stitched area. The distal right coronary artery was of small calibre. The mitral valve seemed normal. Her postoperative recovery was uneventful. The patient subsequently became symptom free. She no longer had a continuous murmur, nor one of mitral regurgitation. Repeat angiography a year after operation showed a dilated right coronary artery with no evidence of a fistula. There was collateral filling of the distal right coronary artery from the left anterior descending artery. Left ventricular angiography showed good left ventricular function with mild mitral regurgitation only. There was no evidence of any intracardiac shunt.

\section{Discussion}

In our patient the left to right shunt was not large $\left(Q_{p}: Q_{s} 1 \cdot 7: 1\right)$, but her dyspnoea completely cleared when the fistula was closed. The dyspnoea was caused by a combination of a left to right shunt, mitral regurgitation, and atrial fibrillation. After operation the mitral regurgitation was also reduced. The reason for this is not clear because the left ventricular function was good, both before and after closure. Harris et al described a patient with normal resting right heart pressures and left ventricular end diastolic pressure. ${ }^{4}$ The pulmonary wedge pressure rose from 6 to $32 \mathrm{~mm}$ $\mathrm{Hg}$ on exercise, suggesting reversible impairment of left ventricular function.

The prognosis in patients with coronary $\frac{T}{\mathbb{T}}$ arteriovenous fistulas depends upon the volume of the shunt, the age of the patient, $\stackrel{c}{-}$ and the presence of any complications. The $\overrightarrow{\widehat{N}}$ abnormality, however, is known to be compatible with a long life. ${ }^{1}$ Though there is a risk of endocarditis, pulmonary hypertension, and $\frac{\bar{s}}{7}$ rupture of the fistulas the risks are small and $\stackrel{\varnothing}{\varnothing}$ not an indication for operation. ${ }^{6}$ In younger क patients it is likely that elective ligation of arteriovenous fistulas may reduce the incidence of late complications. ${ }^{7}$ There are $\vec{\omega}$ also reports of spontaneous closure of $\frac{\mathscr{\Omega}}{\partial}$ arteriovenous fistulas. ${ }^{89}$ In the presence of larger shunts or severe symptoms, however, of

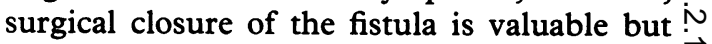
may be difficult especially if there are multiple $\overrightarrow{0}$ communications. ${ }^{5}$ For secure closure of the 0 fistula in our patient the artery was ligated and obliterated at the site of the fistulous T communication. The calibre of the distal right $\frac{\mathbb{D}}{\circ}$ coronary artery was small. Vein grafting was considered but not performed because there was good filling of the right coronary artery $\vec{\oplus}$ from the abnormal circulation of the distal left $\stackrel{\bullet}{-}$ anterior descending artery.

Though the risks of operation are increased in older patients age should not preclude operation. The results were very successful in our 74 year old patient.

1 Gasul BM, Arcilla RA, Fell E, et al. Congenital arteriovenous fistula. Pediatrics 1969;25:53-60.

2 Anderson CP, Adicoff A, Motsay GJ, et al. Traumatic right coronary arterial-right atrial fistula. $\mathrm{Am} \mathrm{J}$ Cardiol 1975;35:439-43.

3 Hobbs RE, Millet HD, Raghavan PV, et al. Coronary artery fistulae: a 10 year review. Cleve Clin $Q$ 1982;49:191-7.

4 Harris A, Jefferson K, Chatterjee K. Coronary arterio- $\bar{J}$ venous fistula with aneurysm of coronary sinus. Br Heart $J$ 1969;31:400-3.

5 Sethia B, Pollock JCS. Coronary artery fistula following rupture of aneurysm of sinus node artery into the right atrium. Thorac Cardiovasc Surg 1985;33:191-2. atrium. Thorac Cardiovasc Surg 1985;33:191-2.
Newcombe CP, Whitaker W, Keates PG. Coronary arterio-
venous fistulae. Thorax 1964;19:16-21.

7 Liberthson RR, Sagar K, Berkoben JP, Weintraub RM, Revine FH. Congenital coronary arteriovenous fistula. 13 patients: review of the literature and delin- $\sigma$ eation of management. Circulation 1979;59:849-54.

8 Griffiths SP, Ellis K, Hordof AJ, Martin E, Levine OR. N Spontaneous complete closure of a congenital coronary $N$ artery fistula. J Am Coll Cardiol 1983;2:1169-73.

9 Hackett D, Hallidie-Smith KA. Spontaneous closure of $\sigma$ coronary artery fistula. Br Heart J 1984;52:477-9. 